\title{
Malignant Adult Brain Neoplasm
}

National Cancer Institute

\section{Source}

National Cancer Institute. Malignant Adult Brain Neoplasm. NCI Thesaurus. Code C5115.

A malignant brain neoplasm occurring in adults. 